\title{
TAXONOMY AND EVOLUTION OF THE ORTHOGRAPTUS QUADRIM- UCRONATUS SPECIES GROUP (GRAPTOLITHINA)
}

GOLDMAN, Daniel, Dept. of Geology, State University of New York at Buffalo, Buffalo, NY 14260.

The Middle to Upper Ordovician graptolite taxon Orthograptus quadrimucronatus currently comprises 11 sub-species and has several closely related species. Many of these subspecies are poorly defined, having been established on the basis of stratigraphic and geographic occurrence and not morphological differences. A detailed morphometric analysis of this group indicates that all 11 subspecies of $O$. quadrimucronatus and the morphologically similar British species, $O$. pageanus, can be placed within three distinct lineages. Members of the $O$. pageanus lineage are characterized by long apertural spines on the first two thecae, a broad proximal end, and a wide less densely thecate rhabdosome. Specimens belonging to the $O$. quadrimucronatus spinigerus lineage have narrow proximal ends, rapidly widening rhabdosomes, and elongated apertural spines on the 8th to $12^{\text {th }}$ thecal pairs. The $O$. quadrimucronatus quadrimucronatus lineage is composed of specimens with no unusual spines and rather parallel sided rhabdosomes.

Orthograptus pageanus first appears in the lower Corynoides americanus Zone and is probably derived from the $O$. calcaratus species group. $O$. pageanus retains the large basal spines, robust rhabdosomes, and long thick nema found in $O$. calcaratus. The thecae of $O$. pageanus are, however, highly derived with respect to $O$. calcaratus whose thecae retain the form of their hustedograptid ancestry. $O$. pageanus has everted thecal apertures and paired apertural spines as opposed to the introverted thecal apertures and apertural horns present in $O$. calcaratus. $O$. quadrimucronatus quadrimucronatus appears at approximately the same time as $O$. pageanus while $O$. q. spinigerus appears slightly later in Australia and Great Britain and several graptolite zones later in eastern North America. The first appearance of all three lineages in the classic graptolite-bearing rocks (Utica Shale) of the northern Appalachian basin represents immigration and not speciation. Members of the $O$. pageanus lineage grow rapidly in size through the $C$. americanus Zone and become extinct at or just above the top of the zone. The $O$. q. quadrimucronatus lineage shows no single trend through time, getting larger and smaller, seemingly in response to changing water chemistry and temperature. Poor preservation of collections of $O$. q. spinigerus make within lineage changes over time impossible to evaluate.

Specimens of these three lineages were examined across an interval of time representing four graptolite zones ( $C$. americanus to $G$. pygmaeus zones) in the Middle and Upper Ordovician rocks of Australia, Great Britain and eastern North America. This interval is generally regarded as having a duration of approximately four million years. Across this interval each of these lineages appears to be a stable entity in space and time. Although there are changes in size among members of a lineage during its existence, there are no basic changes in form. Thus, the anagenetic change in these organisms does not appear to produce any new species or even sub-species. New taxa appear with no evidence of ancestral intermediates, and remain basically the same throughout their duration. This pattern is consistent with punctuated equilibrium, although anagenetic size change is also observed. 